\title{
Simbiose entre tecnologia móvel e patrimônio natural: uma proposta pedagógica
}

\section{Symbiosis between mobile technology and natural heritage: an educational proposal}

\author{
Leandro Baptista; Jasmine Cardozo Moreira
}

\section{RESUMO}

O massivo uso de smartphones está provocando a incorporação destes aparelhos para funções aquém da comunicação. Seja para buscar informações, comprar produtos ou localizar-se em lugares não habituais, os smartphones vem substituindo outros recursos, principalmente devido sua mobilidade. Diante disso, o potencial deste aparelho para práticas educativas, pedagógicas e turísticas é corroborado através do relatório produzido pelo Hosteltur (2013), que, ao elencar as tecnologias que estão afetando a forma que o turismo é praticado, diagnosticou que o acesso a sites de museus, cresceu de 5\% em 2011 para $30 \%$ em 2013, tendendo a se estabilizar em $50 \%$ a médio prazo. Além da navegação na internet, os smartphones oferecem outras possibilidades, através da instalação de aplicativos de acordo com interesses individuais. Diante deste contexto, considera-se a necessidade de aproximar o conhecimento científico de forma holística, ao descrever que: a cada dia erguem-se vozes para denunciar a distância que separa o conhecimento da vida, pois a forma como se desenvolve a educação acentua o isolamento do sujeito a respeito de sua realidade. Sob esta perspectiva, objetivouse com este estudo desenvolver códigos bidimensionais - QR Code (Quick Response Code), que contenham informações sobre atrativos, visando educar os visitantes in situ. Os QR Codes, criados com objetivo de aumentar a quantidade de dados contidos em códigos de barras convencionais, ocupando menor espaço após sua impressão, passou a ser amplamente utilizados em diferentes segmentos ao longo da última década. Assim, utilizou-se como ferramenta para a gerar estes códigos o software invertexto, no qual foram criadas mensagens educativas que auxiliam o visitante a compreender e interpretar a origem das formações rochosas do Parque Estadual de Vila Velha - PEVV (PR), nas cores branca e verde para integrá-los com menor impacto ao meio ambiente e índice de confiabilidade mínima de $93 \%$ para os três principais sistemas operacionais atuais. Os resultados demonstraram que os QR Codes podem ser confeccionados em placas retangulares e verticais, nas dimensões de $23 \times 20 \mathrm{~cm}$, dispostas a aproximadamente $80 \mathrm{~cm}$ do solo, no decorrer da trilha de acesso à formação principal da Unidade de Conservação. Por fim, acredita-se que o uso de smartphones e sua interação com o meio ambiente por meio da tecnologia poderá despertar a curiosidade dos visitantes em descobrir o que os códigos 'escondem', estimulá-los a aprender de forma lúdica e incentivá-los à conservação do local, conscientizando-os das fragilidades existentes no PEV.

PALAVRAS-CHAVE: Tecnologia Móvel; Patrimônio Natural; Turismo Pedagógico; QR Code; Parque Estadual de Vila Velha. 


\section{ABSTRACT}

The massive use of smartphones is leading to the incorporation of these devices to function beyond communication. It's used to looking for information, to buy products or locating in unusual places. Thus the smartphone is replacing other resources, mainly due to their mobility. The potential of this device for educational, pedagogical and tourist activities is stated out by the report produced by Hosteltur (2013), which had listed the technologies that are affecting the way that tourism is practiced and diagnosed that access to museum sites increased from 5\% in 2011 to $30 \%$ in 2013 , tending to stabilize at $50 \%$ in the medium term. In addition to web browsing, smartphones offer other possibilities to use by installing applications according to individual interests. Given this context, it was based in the need to bring scientific knowledge holistically, it is important to fill the gap between the knowledge of life, because the way that develops education accentuates the isolation of the subject about his reality. From this perspective, the aim of this study was to develop twodimensional codes - QR Code (Quick Response Code), containing information about attractions, aiming to educate visitors in situ. QR Codes, created in order to increase the amount of data contained in conventional bars, but occupying less space after printing, became widely used in different segments over the past decade. The tool that it was used to generate these codes was the invertexto software. Educational messages were created to help the visitor to understand and interpret the origin of the Parque Estadual de Vila Velha - PEVV (PR, Brazil) rock formations. It was used the white and green colors, to integrate them with less environmental impact, beyond the minimum reliability index of $93 \%$ for the three major current operating systems. The results shows QR codes with a rectangular form and they were made in vertical signals, with the dimensions of $9.05 \times 7.87$ (in), arranged at approximately 31.49 (in) above the ground. They could be located at the main trail formation at PEVV. Finally, it is believed that the use of smartphones and their interaction with the environment through technology may arouse the curiosity of visitors to find out what the codes 'hide', encouraging them to learn, making them aware about the potential impacts at PEVV.

KEYWORDS: Mobile Technology; Natural Heritage; Pedagogical Tourism; QR Code; Parque Estadual de Vila Velha.

\section{Contextualização inicial}

\section{Turismo em Unidades de Conservação e sua relação com a problemática ambiental}

A pré-história do turismo conserva em sua gênese o deslocamento de viajantes para participarem de eventos e em busca de novos conhecimentos, através da apreciação de monumentos, museus, que permitiam a assimilação de diferentes ideias e projetos. Esta fase foi incentivada com maior ênfase a partir do desenvolvimento dos navios e trens, que permitiu aos membros da classe média e alta complementarem seus estudos durante o chamado grand tour na Europa.

Este resgate parte do pressuposto por diversos autores como o advento do turismo contemporâneo, e, ainda que viajar tenha se tornado uma atividade mais acessível a diversas classes sociais, permanece no imaginário social como uma prática onerosa. Sem entrar no mérito 
econômico, igualmente permanece para os visitantes ou turistas o enriquecimento educacional e cultural adquirido no decorrer de uma viagem.

Neste contexto, as práticas educacionais necessitam de uma abordagem que as diferem do modelo padronizado aluno - sala de aula. $\mathrm{Na}$ educação não formal, realizada em ambientes externos à uma escola ou universidade, as expectativas de crescimento intelectual não se fundamental para a obtenção de um título e sua assimilação não é monitorada por meio de avaliações. Neste, a experiência prática assume uma conotação lúdica e seus efeitos serão mais efetivos quando elementos são interpretados e não decorados.

Assim, o turismo pedagógico apresenta-se como uma ferramenta eficaz para promover o elo entre visitantes e educação sob suas diferentes égides educacionais, em especial em áreas de proteção, que por suas características biológicas e geológicas, exigem maiores cuidados em zonas abertas ao amplo público. Diversos exemplos podem ser citados nesta procura, entre Parques Nacionais consagrados como Fernando de Noronha e o Tijuca, Florestas Nacionais, como a de Tapajós e que estimulam a adoção de estratégias como este fim para promover outras Unidades de Conservação com menor apelo político, mas igualmente importantes, como Parques Estaduais e Municipais.

lgualmente importante, se verifica a adoção de novos programas educativos, que procuram se distanciar de antigas práticas como a condução de guias, a distribuição de matérias gráficos como folders e guias de bolso ou mesmo com a disposição de painéis interpretativos. Diante deste cenário, observa-se a necessidade de adequar as atividades com os mais recentes avanços tecnológicos e que fazem parte da vida social da maioria das pessoas, como computadores e smartphones.

Considera-se que o apelo destes equipamentos é superior aos atuais modelos de gestão de áreas protegidas, estão alicerçados pelo conceito de sustentabilidade, uma vez que estes minimizam a geração de resíduos, mesmo que recicláveis, possuem um menor custo final de produção, além de expandirem o conteúdo das informações de maneira quase infinita, ao serem vinculados a sites oficiais e redes sociais.

Assim, com objetivo de verificar a possibilidade de implantação de um recurso tecnológico, com baixo custo de produção, visando estimular o visitante a adotar medidas como manter o silêncio e evitar a depredação de sítios históricos, desenvolveu-se este estudo de caso no Parque Estadual de Vila Velha (PR), situado no município de Ponta Grossa, como uma proposta ambientalmente sustentável e pedagogicamente responsável.

A metodologia empregada valeu-se de um estudo bibliográfico sobre o segmento turismo pedagógico, novas tecnologias e seu uso para a educação não formal. Esta etapa serviu para subsidiar a construção da fundamentação teórica em que os resultados se apoiam, respeitando assim a literatura vigente e procurando contribuir para abordagens mais recentes e atualizadas sobre os temas estruturantes.

A segunda etapa do estudo consistiu em duas saídas técnicas ao Parque Estadual de Vila Velha (PR), onde foi percorrida a trilha principal do 
Parque de início ao fim quatro vezes, nos dias 08 de agosto de 2016 e 10 de agosto de 2016. Na visita primária foram identificados os pontos passíveis de interpretação, documentados através de fotografias. A segunda visita visou corroborar os temas desenvolvidos em laboratório e sua efetiva possibilidade de implantação.

Por fim, em laboratório foram desenvolvidos QR Codes com frases que visam estimular o comportamento sustentável do visitante durante 0 momento que está no Parque Estadual de Vila Velha, bem como sensibilizálo após deixar a Unidade de Conservação. Concentraram-se esforços em criar frases curtas, sem que transparecessem restritivas, com intuito de tocar os sentimentos e a curiosidade das pessoas sobre temas de interesse a uma área natural protegida como a importância em não coletar coisas no local, evitar tocar áreas frágeis e evitar barulhos exagerados.

Os resultados indicam que a utilização de QR Codes para a educação em campo é uma alternativa válida para o PEVV, sendo de baixo custo, complementar às ações já existentes, provocam a curiosidade e a interação dos visitantes para descobrirem o que há por trás dos códigos apresentados. Assim, são lançadas algumas sugestões de aplicação desta tecnologia na UC, bem como seus locais para a efetiva implantação.

\section{Turismo pedagógico enquanto atividade educacional}

No cerne do turismo concentra-se uma atividade fundamentalmente recreativa e educacional, observado desde a sua gênese com as viagens para participação em jogos e posteriormente com o grand tour, onde deslocava-se com o intuito de conhecer os legados históricos, transvestidos sob a ótica do patrimônio pelo continente europeu.

Portanto, enquanto atividade educativa, o turismo caracteriza-se pelo segmento pedagógico, mercado que, segundo dados do Cadastro Nacional de Prestadores de Serviço do setor (Cadastur), mais que dobrou entre os anos 2009 e 2014, passando de 945 para 2.129 agências de viagem que operam sobre estudos e intercâmbio, uma alta de aproximadamente 125\% (MINISTÉRIO DO TURISMO, 2014).

O turismo pedagógico se configura por viagens programadas dentro do calendário escolar, atuando como um elemento complementar à teoria aprendida em sala de aula e que deve ser complementado por exercícios programados, como relatórios passíveis de aplicação de avaliações e lançamento de notas. Sua concepção é abordada por Beni (2004), ao definir que consiste na organização de viagens acompanhadas por professores, com programas de aulas e visitas a pontos históricos ou de interesse para o desenvolvimento dos estudantes, bem como de estudos de ecossistemas, entre outros aspectos do meio ambiente.

Nakamura e Machado (2012, s/p) destacam o papel integrador que o turismo pode proporcionar ao ser incorporado ao ensino, pois 
O Turismo Pedagógico procura apresentar aos estudantes a oportunidade de aprender na prática o que foi visto nos conteúdos trabalhados em sala de aula. E preciso instituir um sentido significativo às experiências pedagógicas, porque enquanto o conhecimento for ilustrado de forma fragmentada, como parte da realidade, permanecerá sempre inacabado. Através da utilização desse mecanismo facilitador do processo ensino-aprendizagem, o que mais chama a atenção é a possibilidade de se trabalhar efetivamente a interdisciplinaridade, saindo dos limites da sala de aula e apresentando um mundo de referências reais palpáveis.

Atualmente existem diversos programas com este intuito, principalmente em cursos superiores. Exemplifica-se este incentivo através do programa permanente de extensão da Universidade Estadual do CentroOeste (UNICENTRO), onde o Departamento de Turismo promove o receptivo de alunos em seu campus (Irati) e os conduzem pelos diversos laboratórios e áreas de ensino da instituição, personalizando o roteiro de acordo com o que os professores estão lecionando nas suas escolas.

Outro projeto que envolve a abordagem da Educação Ambiental é desenvolvido pela Universidade Estadual de Ponta Grossa (UEPG), em que alunos do curso de bacharelado em turismo são sensibilizados quanto à sustentabilidade e a proteção de mananciais ao realizarem mutirões de limpeza de rios em um Parque Nacional situado no município (TELES; SANTOS; MOREIRA, 2014).

Neste contexto de ensino, identifica-se que os alunos podem ser abordados por novas formas didáticas, para que a aprendizagem se configure em uma atividade espontânea e prazerosa. Corrobora-se esta premissa através da Organização Mundial do Turismo, quando considera que determinados roteiros podem ser considerados como propícios ao segmento, quando

(...) voltados para locais históricos, culturais ou científicos importantes, e muitas vezes são coordenados por um professor especializado. Ao contrário da simples visita a locais turísticos, os roteiros educacionais podem incluir livros, palestras e outros materiais complementares para criar uma experiência de aprendizagem mais formal (OMT, 2003, p.90-91).

Transborda-se, contudo, a percepção da OMT (2003) sobre os locais identificados considerados aptos para a prática do segmento. Além das vertentes citadas, entende-se que outros temas transversais também podem ser trabalhados com ações externas ao ambiente escolar, como a geografia, geologia, história, sustentabilidade, meio ambiente, entre outros. Milan (2007, p.32-33) descreve as contribuições que esta atividade oferece aos alunos: 
a) O psicológico, porque suas vivências e comportamentos estão sujeitos a mudanças por influência do turismo, alterando objetivamente as motivações, preferências, valores e atitudes enquanto "futuros cidadãos";

b) O sociológico, porque suas observações e relações no meio em que vivem são interativas com o turismo como fenômeno social, proporcionando novos contatos, experiências e integração entre os alunos, com os professores e com a comunidade em geral;

c) O cultural, pois o conhecimento do patrimônio históricocultural e o contato com outras culturas, tradições, hábitos e costumes da população local transformam-se em experiência enriquecedora, promovendo o intercâmbio entre visitantes e visitados;

d) O ambiental, porque a apreciação gera consciência para aumentar a preservação da herança natural como fator de potencial turístico da localidade.

A autora destaca também que o Turismo Pedagógico é uma forma de propor ao aluno uma participação ativa no processo de construção do conhecimento, pois oferece meios para que ele possa tornar-se um cidadão criativo, dinâmico e interessado em atuar, de forma efetiva, na comunidade, contribuindo para o desenvolvimento de uma sociedade mais consciente em todos os níveis (MILAN, 2007).

Diante deste contexto, a prática do turismo que incorpora em suas atividades a participação ativa de seus visitantes, vem se apresentando como objeto cada vez mais relevante nos itens de preocupações de gestores de destinações ou áreas de interesse turística, que procuram enriquecer a experiência das pessoas para que estas, retornem às suas residências com aprendizados, carregando consigo o "souvenir" do conhecimento. Tal preocupação tem por fundamento diminuir os impactos negativos decorrentes do crescimento desordenado do turismo.

Procura-se propor desta maneira, que novas abordagens sejam lançadas à educação em campo, facilitando o processo de aprendizagem mesmo quando o visitante conhecer um local sem o auxílio de um professor, transformando a experiência do mesmo durante seu momento de descanso ou férias. Procurando alcançar este objetivo, o próximo tópico trata da incorporação de tecnologia para auxiliar neste processo, devido sua popularização em todo o globo.

\section{Inovações tecnológicas e turismo}

Os avanços tecnológicos ocorridos nas diferentes áreas de conhecimentos proporcionaram mudanças de ordem comportamental, de estímulo e de tendências para o turismo. Para exemplificar estes avanços, pode-se ilustrar através das diferentes formas de produção e armazenamento de energia, como alteraram a vida humana, pois é inteligível 
que as viagens iniciadas com o suporte de animais foram substancialmente modificadas após a popularização dos motores à vapor, que mais uma vez, foram alteradas com a incorporação de combustíveis fósseis para 0 deslocamento.

Estas revoluções da engenharia não foram desenvolvidas com intuito de favorecer o turismo, mas para sanar dificuldades do sistema de produção existentes. Contudo, como efeito colateral, provocaram profundas mudanças na forma de viajar, diminuindo o tempo necessário para chegar a um destino, por conseguinte, permitindo percorrer maiores distâncias em um único período.

Além da modernização dos meios de transporte, a atividade também foi profundamente impactada pelas constantes transformações que ocorreram e continuam em curso na comunicação. Se um dos desafios do turismo é atenuar sua intangibilidade, uma vez que não pode ser testado ou provado no momento da compra, o uso de materiais de divulgação como matérias em revistas especializadas, fotos da paisagem de atrativos, vídeos institucionais e a internet são exemplos de contribuição para a aproximação do visitante com o destino.

Entre as ferramentas de divulgação, pode-se considerar que internet é aquela que mais provocou mudanças na forma de se vender o turismo. Seu surgimento data do século $X X$, com intuito de uso inicial para fins militares, tendo seu desenvolvimento vinculado a uma parceria entre a força militar, o campo científico e as iniciativas tecnológicas (CASTELLS, 2001).

A internet permitiu que a transmissão de informações e a comunicação entre pessoas se tornassem mais rápidas, colocando-as em contato com diversas opções de lazer, estudos e elementos culturais, ampliando e fortalecendo o contexto da globalização, a mesma também serviu para alterar a forma de se fazer negócios, barateando custos e remodelando organizações (TRIGO, NETTO, 2003).

Estes avanços foram sentidos em todo o trade turístico, sobretudo na forma de gerenciar deslocamentos, com a implantação de sistemas de reservas de voo, que pode ser apontado como um dos primeiros softwares destinados exclusivamente à atividade e posteriormente, soluções para agências de viagens e hotéis.

Pode-se inferir que após a popularização da informática, incentivada pela crescente necessidade social em manter-se conectada à internet pelos mais diversos motivos como acompanhar notícias, previsões meteorológicas, situações de trânsito, oscilações de preços de produtos ou mesmo para ocupar o tempo enquanto aguarda a conclusão de um serviço, mudaram a forma de encontrar informações no atual contexto contemporâneo.

Boa parte desse consumo de dados se deve ao contínuo desenvolvimento de aparelhos móveis como os smartphones, que oferecem recursos integrados com um custo acessível, eximindo na maioria das vezes, a necessidade de carregar consigo mais do que um único equipamento. 
A incorporação de tecnologia móvel fez com que novas formas de uso fossem desenvolvidos para estes aparelhos, não se limitando mais à realização de chamadas ou ao envio de SMS, funções prioritárias nos celulares da década passada. Assim, a comunicação digital deixou de ser uma tendência, e independentemente do tipo de conteúdo digital que o usuário necessita acessar, há uma propensão das empresas em atender seu cliente por meio de equipamentos móveis.

Além da praticidade em carregar um aparelho de pequeno porte, os smartphones cada vez mais são equipados com processadores e memória de gravação e leitura de dados que se comparam aos computadores pessoais. Portanto, ignorar o uso desta tecnologia ou até mesmo deixa-la em segundo plano significa deixar de competir e de explorar na totalidade este canal de comunicação.

Procurando evidenciar a diversidade de possibilidades que a mobilidade existente no século XXI permitiu a humanidade, Diniz (2010, p. 67) destaca:

Agricultores do estado do Paraná recebem a previsão de geadas em seus celulares, permitindo que se preparem com antecipação para proteger as suas lavouras. Turistas em Salvador, durante o carnaval, utilizam seus celulares para acompanhar as atividades dos circuitos dos trios-elétricos. Pais de alunos no Rio de Janeiro recebem mensagens em seus celulares sobre os filhos com problemas de frequência na escola. Policiais do estado do Pará checam a situação de um carro suspeito, digitando a sua placa em um telefone celular. Índios no estado da Bahia utilizam seus celulares para medirem as condições da água do mar em que cultivam ostras.

Estas características demonstram que o aparelho de celular passou a cumprir inúmeras funções diferentes do que a sociedade estava acostumada a esperar de um telefone: realizar e receber chamadas. Assim, a versatilidade que os smartphones adquiriram ao longo dos últimos anos tornou este recurso essencial para o planejamento de variadas atividades, como exemplificadas por Diniz (2010).

O potencial deste mercado para o turismo é também corroborado através do relatório produzido pelo Hosteltur (2013), que elencou vinte das principais tendências tecnológicas que estão afetando diretamente a forma que a atividade turística é praticada. A primeira influência citada do documento traz o resultado de um estudo sobre o acesso a sites de destinos turísticos e museus na Espanha, onde o tráfego nas páginas a partir de dispositivos móveis foi em 2011 de apenas 5\%, passando para 16\% em 2012 e sendo estimado para mais de 30\% em 2013 (dados ainda não publicados), tendendo a estabilizar em torno de $50 \%$ do tráfego total em médio prazo.

Este mesmo estudo também mostrou que a maior parte dos acessos se deu através de smartphones e não por meio de tablets. Contudo, quando 
analisadas as páginas geradas para os dispositivos móveis, percebeu-se que esta não possui a mesma qualidade de quando é acessada por meio de um computador ou notebook, permitindo assim a compreensão de que muitos sites não estão preparados para receber tal fluxo de maneira satisfatória (HOSTELTUR, 2013).

Ao considerar o quantitativo de vendas que os smartphones vêm alcançado somente no Brasil, onde foram comercializados entre julho e setembro de 2014 quinze milhões de unidades, percebe-se um grande nicho de mercado a ser contemplado. O principal motivo para o incremento no número de pessoas que passaram a utilizar estes aparelhos reside no valor de compra do mesmo, que vem paulatinamente decrescendo ao longo dos anos (DIÁRIO DE PERNAMBUCO, 2014).

Contudo, além do uso destes dispositivos móveis para o acesso e navegação à internet, eles oferecem também diversos recursos através de aplicativos que são instalados de acordo com os grupos de interesse de cada indivíduo, sendo estes, grandes incentivadores de compra dos smartphones.

Diante deste contexto, corrobora-se com Droguett (2004, p. 13), quando o autor demonstra interesse em aproximar o conhecimento científico de forma holística, ao descrever:

\begin{abstract}
A cada dia que passa, erguem-se vozes para denunciar a grande distância que separa o conhecimento da vida. Efetivamente, a forma como se desenvolve o processo de educação, hoje em dia centrado em disciplinas técnicas e compartimentadas, acentua 0 isolamento do sujeito a respeito de sua realidade social, econômica e política (...), o exercício interdisciplinar é a via mais promissora para a conquista de um saber sobre a sua interação com o espaço.
\end{abstract}

Portanto, verifica-se a possibilidade de incentivar o uso destes recursos para funções que vão além do compartilhamento de dados em redes sociais, promovendo um link entre os já populares smartphones com conteúdos que contribuirão na formação educacional das pessoas, principalmente quando estão em momentos de lazer, onde o fato de aprender pode se transvestir em uma brincadeira. Sob esta ótica Droguett (2004, p. 14) ressalta ainda aquilo que julga como os mais graves problemas da atual conjuntura social, ao justificar a necessidade de uma visão interdisciplinar, quando:

Os problemas mais graves que afetam a nossa sociedade: a degradação do meio ambiente, as ameaças nucleares, a fome, a exploração do solo, o desemprego, não se situam no marco isolado de uma disciplina especifica. Sua magnitude e complexidade exigem o estudo e a procura incessante de um diálogo inter, multi e transdisciplinar para soluções. 
Neste sentido, os aplicativos parecem possuir atratividade suficiente para agregar valor a um determinado produto ou serviço, embutindo neste, elementos que farão o visitante entender in loco 0 que se procura sensibilizar. Por exemplo, atualmente é bastante comum se deparar com QR Code (Quick Response Code) que demonstram a origem de um produto ou ampliam o conhecimento do cliente sobre o mesmo, fortalecendo a imagem de uma empresa/destinação.

O QR Code trata-se de uma representação bi-dimensional de dados, superando assim a quantidade de informações contidas em código de barras tradicional. Para que o consumidor consiga interpretar os dados ali contidos, é necessário o uso de um aplicativo.

Desenvolvido em 1994 pela empresa japonesa DENSO, com o objetivo de aumentar a quantidade de informações contidas em um código de barras tendo em contrapartida, a ocupação de um menor tamanho impresso, os QR Codes aumentaram a velocidade de processamento dos leitores, evoluindo assim, os métodos de gerenciamento de estoque dos mais diversos segmentos de mercado. Contudo, sua aplicabilidade inicialmente destinada ao armazenamento em indústrias, passou a ser utilizada com maior frequência por empresas de diferentes mercados ao longo da última década.

Os códigos são desenvolvidos por matrizes e possuem uma linguagem em duas dimensões - 2D, fato este, que permite que os dados sejam alimentados tanto em sentido vertical quanto na horizontal, ampliando assim sua capacidade de armazenamento em relação aos códigos de barra tradicionais, que são lidos unicamente em sentido horizontal (Figura 1).

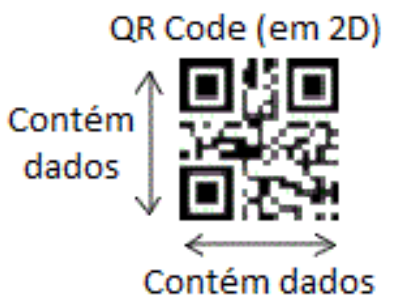

Código de Barra

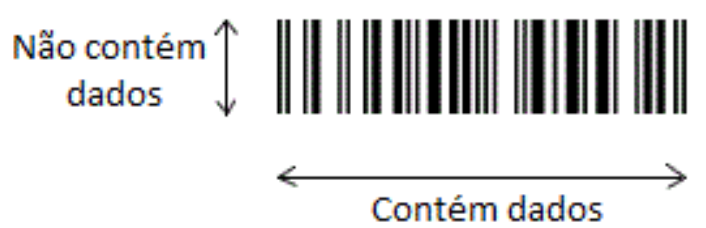

Figura 1: Alimentação de dados no QR Code e em Código de Barra.

Figure 1: Data feed on the QR Code and Barcode.

Fonte: DENSO-WAVE, 2015. Adaptado pelos autores.

Source: DENSO-WAVE, 2015. Adapted by the authors.

Portanto, O QR Code pode aumentar o bojo de informações de um produto, seja em função de preços, links para websites, comparativos entre outros produtos, detalhes sobre a sua produção, entre outros, através do uso de um celular com câmera e um aplicativo de leitura do código instalado.

Para ações de utilização pelo turismo, identificam-se diversas oportunidades de vinculação desta tecnologia para ampliar a experiência dos visitantes, como sua incorporação em painéis interpretativos, no decorrer de 
trilhas autoguiadas, em produtos diversos disponíveis no centro de visitantes, em passaportes temáticos de uma região, entre outros.

A vantagem desta tecnologia também reside no fato de que o visitante não terá conhecimento de suas informações até que realize seu escaneamento, evitando assim, que imagens pré-concebidas influenciem na interpretação de locais. Sobretudo em áreas que formações rochosas, elementos geológicos ou elementos paisagísticos permitem uma livre leitura do espaço, onde elementos simbólicos e sentimentais poderão compor a personificação de atrativos de forma individual e portanto, acrescentar maior valor à experiência daquela viagem.

\title{
Inovações tecnológicas e turismo
}

O Parque Estadual de Vila Velha (PEVV) é a primeira Unidade de Conservação estadual do Paraná, criada em 1953 e abriga em sua área de 3.122,11 ha, a coexistência de diferentes ecossistemas como campos, floresta com araucária e refúgios do cerrado, sendo os dois primeiros típicos região dos Campos Gerais. Além de sua biodiversidade, destacam-se nesse local elementos da geodiversidade, como relevos de exceção (Arenitos e Furnas) e exposições de unidades geológicas sedimentares silurodevonianas da Bacia do Paraná (MELO, 2000 apud MOREIRA, 2008).

Os principais atrativos para visitação no PEVV estão relacionados à exemplares abióticos. De acordo com o Serviço Geológico do Paraná (MINEROPAR, 2016, s/p):

\begin{abstract}
Os monumentos geológicos encontrados em Vila Velha são constituídos por uma rocha denominada arenito, o Arenito Vila Velha, formado pela compactação e endurecimento de camadas sucessivas de areia, pertencentes à unidade geológica denominada Grupo Itararé. A formação destes arenitos remonta há 300 milhões de anos no Período Carbonífero, quando a América do Sul ainda estava ligada à África, à Antártida, à Oceania e à Índia, formando um grande continente chamado de Gondwana. Nesta época, a região onde se localiza Vila Velha estava mais próxima ao Polo Sul e a temperatura média na Terra era muito baixa, período que corresponde a uma das grandes eras glaciais do passado terrestre denominada glaciação gondwânica permo-carbonífera.
\end{abstract}

O modelamento dos arenitos que compõem o PEVV é recente, datando do Período Quarternário (últimos 1,8 milhão de anos). Sua característica é a presença de relevo em forma de ruínas (ruiniforme), marcado pela associação de formas como caneluras, cones de dissolução, topos pontiagudos, torres e pilares, que originam esculturas naturais (MINEROPAR, 2016), das quais a Taça é a forma mais conhecida do Parque, sendo também usada como símbolo e identidade do município de Ponta Grossa (PR), que abriga o PEVV. Além da Taça, outras formas 
curiosas (que remetem à barcos, indígenas, animais e objetos), são encontradas nas trilhas do Parque.

Como é observado na Figura 2, em um exercício livre de interpretação, observa-se que as rochas lembram o modelamento de uma Taça, a cabeça de um camelo ou dromedário e por fim, uma bota.

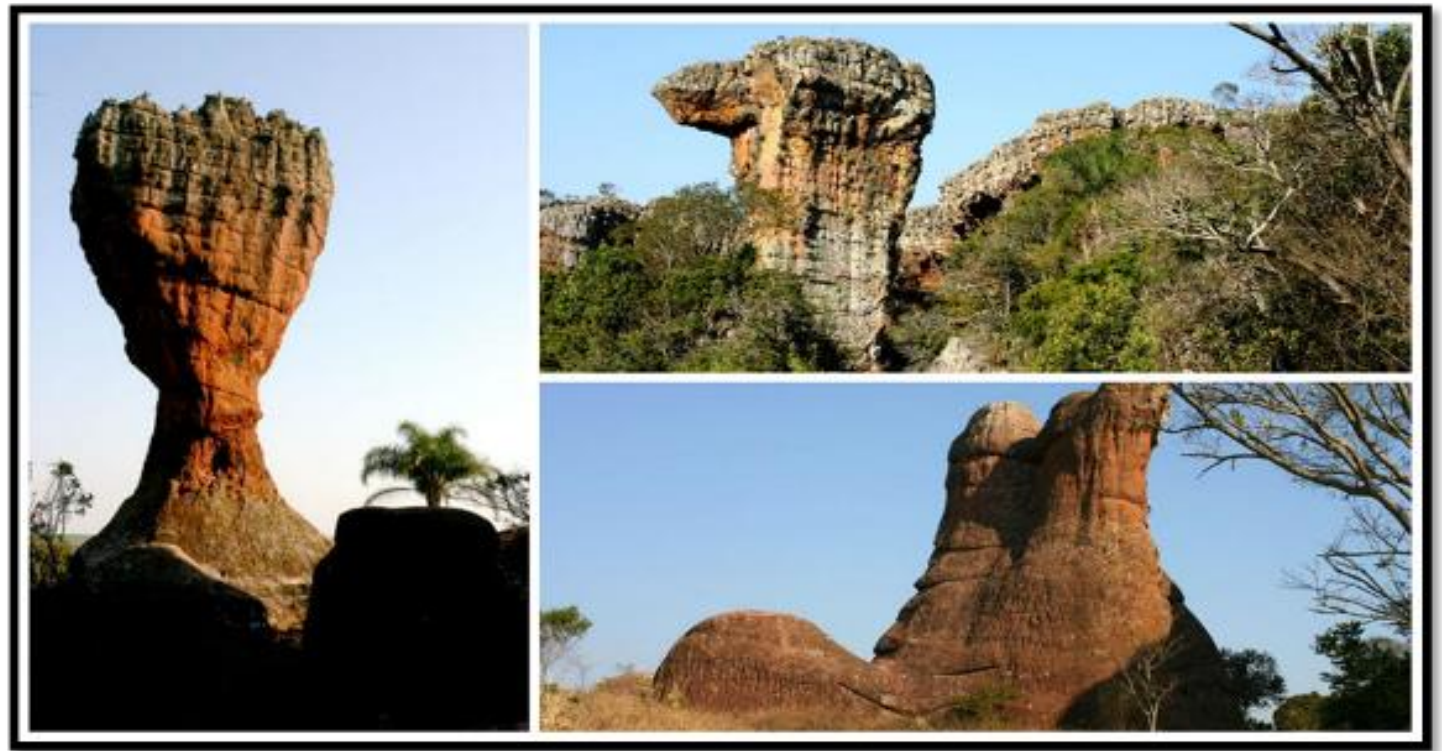

Figura 2: Alguns exemplos de feições rochosas no PEVV.

Figure 2: Examples of rock formations at the PEVV.

Fonte: Prefeitura Municipal de Ponta Grossa (2016). Source: Ponta Grossa City Hall (2016).

O PEVV está localizado no segundo planalto paranaense, na região denominada Campos Gerais, às margens da rodovia BR-376, corredor viário que permite o acesso ao litoral do estado e à capital Curitiba $(80 \mathrm{~km}$ do PEVV). A Figura 3 ilustra a localização do Parque Estadual de Vila Velha.

Há alguns anos, antes ainda da revitalização do Parque que aconteceu em 2002, havia ao longo das trilhas pequenas placas que continham estas informações, visando facilitar a visualização dos exemplares. Contudo, essas placas foram retiradas, motivadas pelo interesse em não influenciar a visita, permitindo assim que os visitantes interpretem os arenitos com base em seus valores, suas percepções e suas experiências.

Assim, a educação ambiental no PEVV é realizada por meio de visitas guiadas, uma vez que o Parque conta com guias e monitores que auxiliam os visitantes. Além dos guias, há a disposição materiais de apoio, como folders e dois painéis interpretativos relativos à geologia, contudo, além destes painéis apresentarem textos com uma linguagem não acessível para o amplo público, são também pouco ilustrados, não atraindo assim, a atenção dos visitantes, principalmente de crianças (MOREIRA, 2008). A Figura 4 ilustra o início da trilha dos arenitos e seu painel (esquerda) enquanto a imagem à direita detalha o painel localizado na saída do estacionamento. 


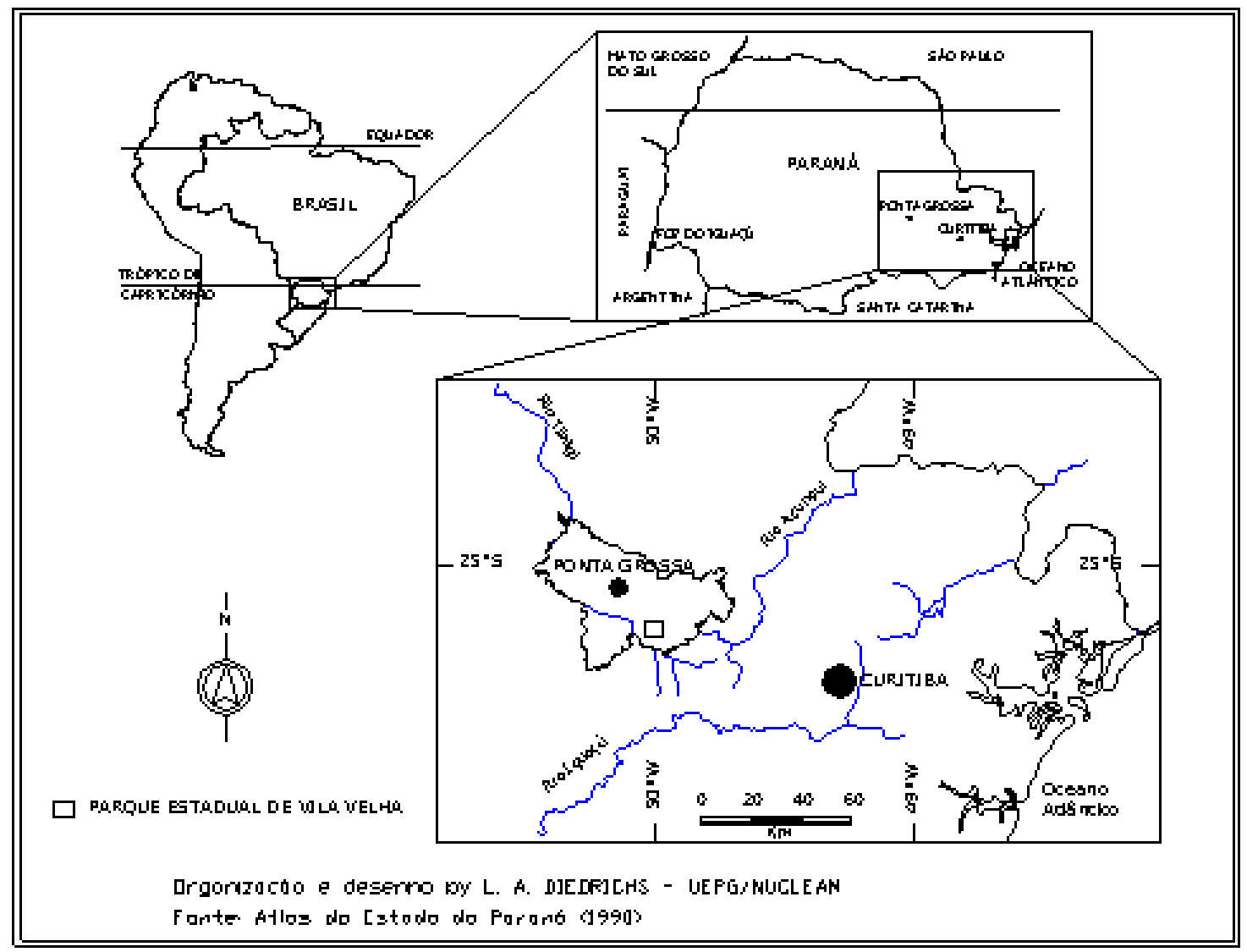

Figura 3: Localização do PEVV. Fonte: Melo et al. (1999).

Figure 3: PEVV's location. Source: Melo et al. (1999).

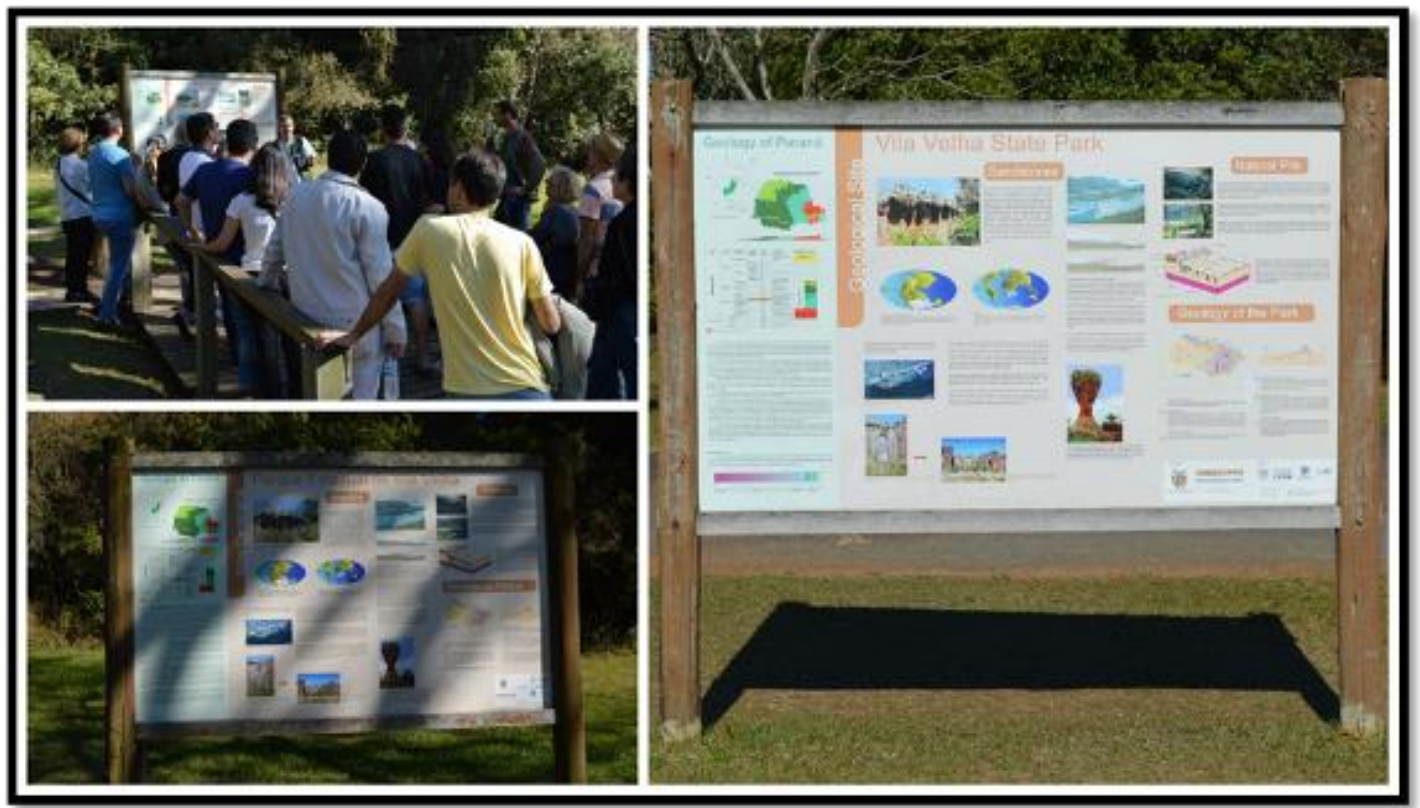

Figura 4: Painéis dispostos na Unidade de Conservação. Fonte: Autores (2016).

Figure 4: Interpretative panels arranged in Protect Area. Source: By authors (2016). 
A trilha principal do PEVV tem aproximadamente 2.700 metros, iniciada na área dos Arenitos e tem seu término neste mesmo local. É levemente sinuosa, que por vezes aproxima o visitante das rochas, construída em alvenaria, e na sua primeira parte (início até a formação Taça) possui sete degraus, comprometendo assim sua realização por pessoas com mobilidade reduzida ou portadores de necessidades especiais. $\mathrm{Na}$ continuidade da mesma, chamada de trilha do bosque, existem outros 201 degraus.

Conforme apresentado, devido às particularidades locais (arenitos) e as deficiências de acessibilidade na zona de uso público, percebe-se que o principal atrativo do local necessita de elementos que contribuam na interpretação para os visitantes. Esta questão torna-se ainda mais relevante por se tratar de atrativos abióticos, que em geral, possuem menor afetividade entre as pessoas, se comparado aos locais com variedade de fauna e flora, por exemplo. Assim, se reconhece e se justifica a necessidade de dinamizar os meios educativos, sem a substituição das ferramentas já existentes na UC.

\section{Resultados e discussões}

Diante do exposto, considerou-se que o Parque Estadual de Vila Velha é um local que tende a ser mais valorizado e utilizado por moradores locais e turistas se sua zona de uso público for melhor estruturada para atender diferentes perfis de visitantes. Como já existem painéis interpretativos que tratam da formação dos Arenitos, Furnas e Lagoa Dourada, bem como há guias e monitores para a realização de atividades personalizadas, os QR Codes podem complementar esta oferta, estimulando também a curiosidade das pessoas em descobrirem o que os códigos "escondem".

Para efeitos dessa pesquisa, foram considerados quatro pontos para a disposição de placas retangulares e verticais, nas dimensões de $23 \times 20$ $\mathrm{cm}$, dispostas a aproximadamente $80 \mathrm{~cm}$ do solo, no decorrer da trilha de acesso à formação principal da Unidade de Conservação, que leva à Taça. Ao contrário dos QR Codes tradicionais, em cores branca e preta, optou-se para a criação dos mesmos nas cores verde e branca.

A opção pela quantidade de placas, formato, altura do solo e cores possuem as seguintes conotações:

a) A trilha possui aproximadamente 1.000 metros, portanto, cada placa estará disposta em um intervalo de cerca de 250 metros uma da outra, visando não saturar o interesse dos visitantes;

b) o QR Code se constitui como um quadrado, e a sua impressão em um plano vertical permite uma melhor adequação ao design do mesmo e também à inserção da logo oficial do Parque;

c) a altura permite o acesso a diversos perfis de visitantes, como adultos e crianças; 
d) a opção pela trilha principal do PEVV se dá em função da UC receber também visitas noturnas, onde somente esta trilha é utilizada. Porém, a ampliação do projeto pode contemplar demais áreas no futuro;

e) a cor verde foi tomada como referência para integrar as placas ao ambiente em que serão inseridas, procurando manter a harmonia paisagística.

Não haveria importância em disponibilizar os QR Codes se estes apenas tratassem de auxiliar o visitante a interpretar a forma rochosa do Parque, uma vez que o condutor pode auxiliar neste processo e o objetivo primordial é que cada pessoa, à sua maneira, procure soltar sua imaginação na interpretação do local. Assim, informações sobre o tempo que o local foi formado, suas fragilidades, curiosidades, entre outros são enfocadas.

O primeiro ponto para a implantação da placa se trata da ambientação temporal que PEVV possui. Atributos gerais da UC, demonstradas por meio de vídeo no Centro de Visitantes antes do início da caminhada devem ser reforçadas no momento de interação direta com o sítio. Portanto, procurou-se vincular a necessidade de conservar o local devido ao seu tempo de existência, para que o visitante perceba o dano que irá causar caso realize algum tipo de depredação, como o lançamento de resíduos ou a coleta de materiais do Parque. Para tanto a frase escolhida foi: "Você está em uma área formada há mais de 1,8 milhões de anos! Ajude a natureza a mantê-la para que outros também possam desfrutá-la!"

O ponto onde sugere-se sua implantação (à esquerda) e o código gerado com a frase são observados na Figura 5:

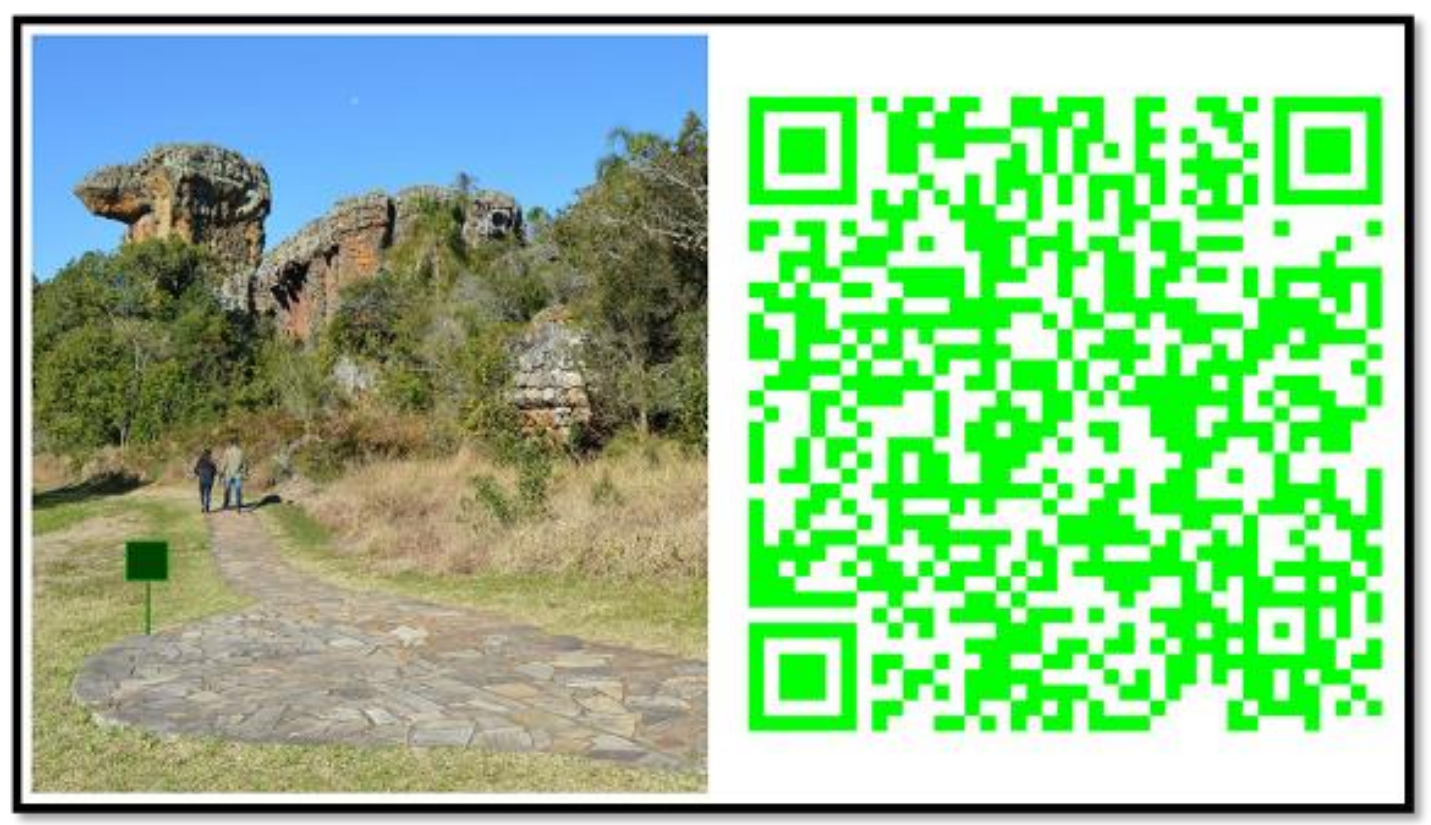

Figura 5: Primeiro ponto interpretativo e seu QR Code. Fonte: Autores (2016).

Figure 5: First interpretative place and it's QR Code. Source: By authors (2016). 
O segundo local remete ao ponto em que os visitantes mais se aproximam dos arenitos no decorrer da trilha, alertando para a mitigação de um impacto comumente observado, onde as pessoas tocam a rocha durante sua caminhada.

Assim, o objetivo desta placa é informar sobre a composição da rocha e alertar para sua fragilidade, procurando evitar ou diminuir as ações antrópicas. Neste ponto, acredita-se que a frase "As rochas de Vila Velha são formadas por várias camadas de areia! Por ser tão frágil, procure não tocá-las!" pode contribuir na educação ambiental através da sensibilização proposta (Figura 6).

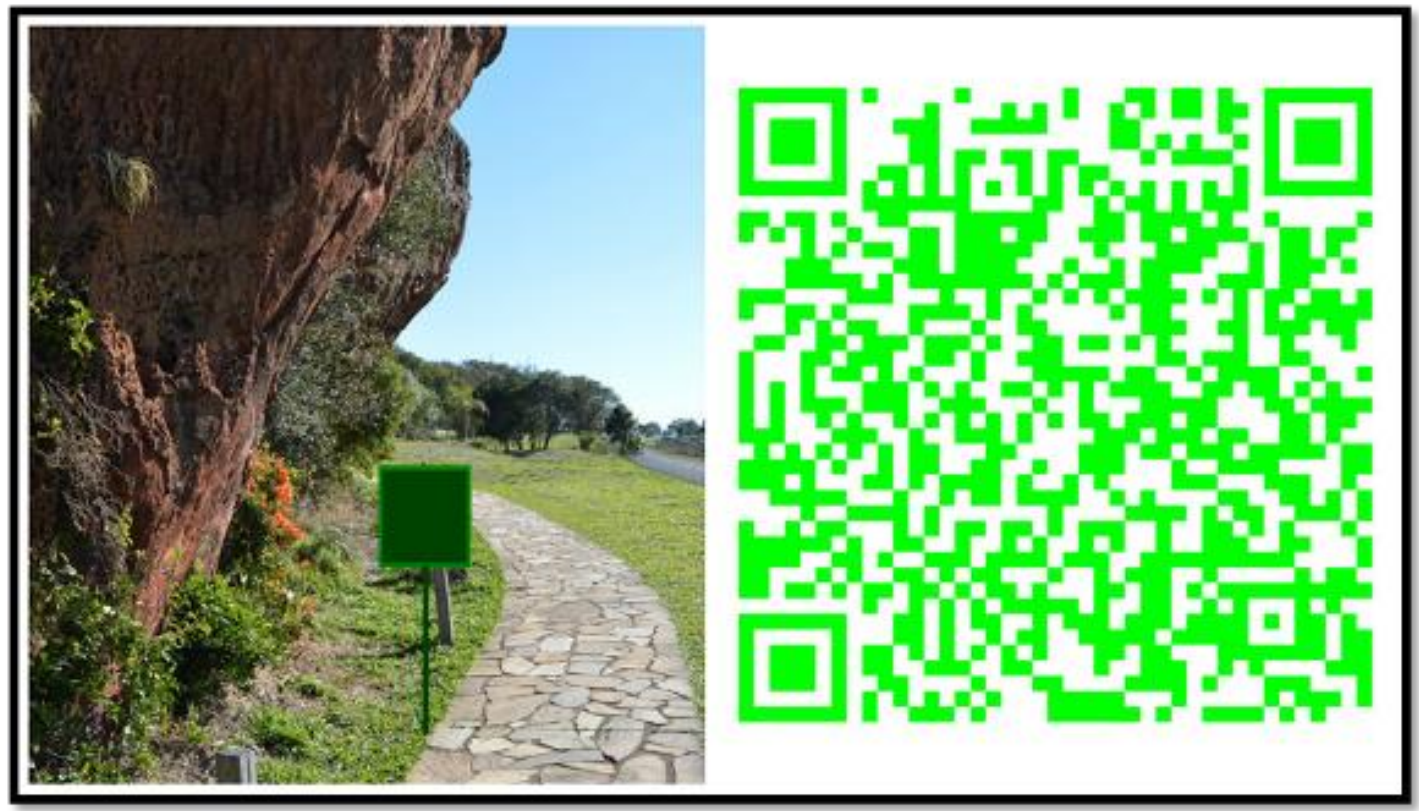

Figura 6: Segundo ponto interpretativo e seu QR Code. Fonte: Autores (2016).

Figure 6: Second interpretative place and it's QR Code. Source: By authors (2016).

Em seguida, busca-se sensibilizar para a necessidade de manter o silêncio enquanto a trilha é percorrida. Utilizando-se dos elementos da fauna presentes no PEVV, os visitantes são estimulados a procurarem por animais que ali vivem, tendo em contrapartida que diminuir os sons que emitem, uma vez que estes podem fazê-los fugir.

Considerou-se que esta recompensa em potencial pelo silêncio pode encorajar os visitantes a respeitar o pedido, e agirem de acordo com o que é esperado em uma Unidade de Conservação, visando sobretudo, minimizar os impactos gerados pelo uso público. Assim, a mensagem gerada foi "Há uma vasta fauna em Vila Velha, como lobos-guará, jaguatiricas, quatis, veados e tatus. Mantendo silêncio pode ser que você os encontre!", como observado na Figura 7. 


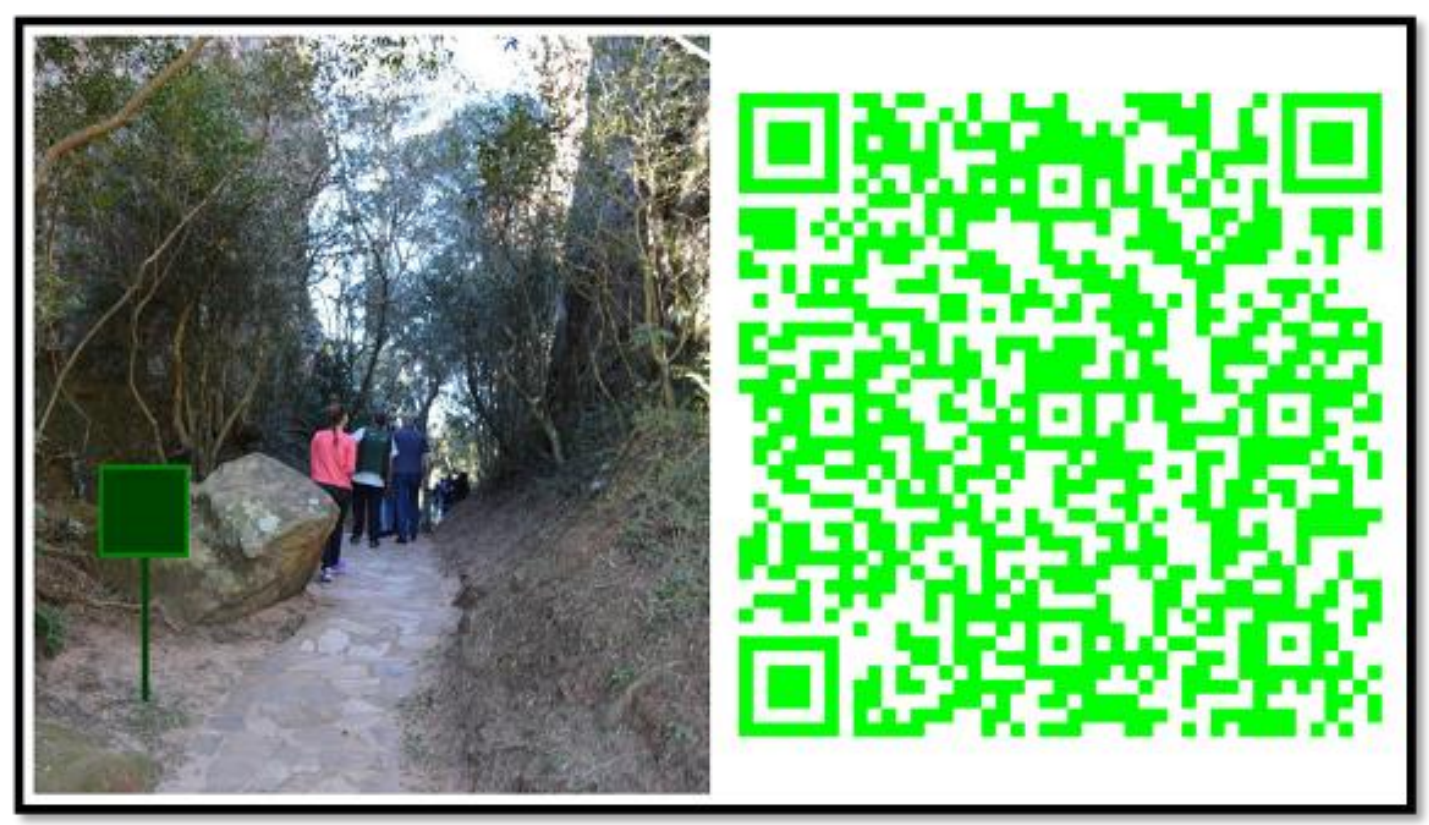

Figura 7: Terceiro ponto interpretativo e seu QR Code. Fonte: Autores (2016).

Figure 7: Third interpretative panel and it's QR Code. Source: By authors (2016).

Finalmente, ao chegar na principal formação do Parque Estadual de Vila Velha, os visitantes costumam permanecer mais tempo que em outros locais, seja pela contemplação ou pela busca no ângulo ideal para fotografar. A taça, ícone da Unidade de Conservação e também símbolo representativo da cidade de Ponta Grossa, está envolta em lendas e possui elementos que fortalecem sua beleza cênica, que despertam o interesse dos turistas em saber se ela um dia também sofrerá com as condições naturais a ponto de desabar.

Partindo do pressuposto que este ponto tem um valor simbólico também para os visitantes do PEVV, que poderão compartilhar principalmente esta imagem em redes sociais e círculos de amizades, procurou-se permitir um canal de comunicação entre os visitantes e a UC, com objetivo secundário de realizar um marketing indireto sobre o Parque. Cabe a ressalva que as fotos da visita somente podem ser publicadas no perfil oficial do Parque no Facebook, uma vez que não conta com um site próprio.

Neste cenário, a Figura 8, demonstra a localização da placa e a frase em QR Code traz a mensagem "Você chegou ao principal atrativo, a Taça! Que tal compartilhar uma foto da sua visita conosco? Nossa página no Facebook está recheada de outros amantes da natureza como você! Acesse https://www.facebook.com/parquevilavelha". 


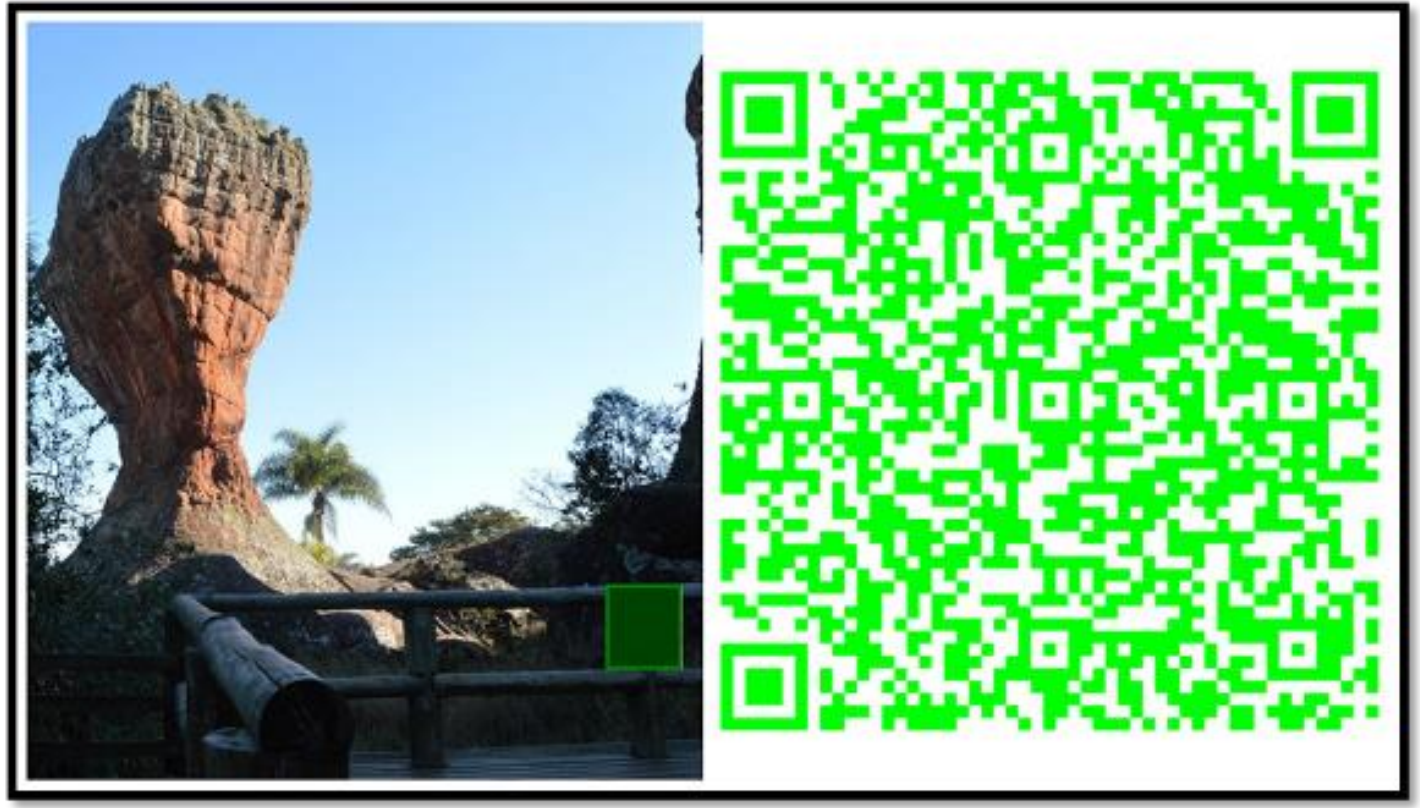

Figura 8: Último ponto interpretativo e seu QR Code. Fonte: Autores (2016).

Figure 8: Last interpretative place and it's QR Code. Source: By authors (2016).

Assim, finaliza-se a proposta interpretativa para o PNCG, considerando que o mesmo apresenta condições e viabilidade para implantação e manejo.

\section{Considerações finais}

Conforme apresentado, os recursos tecnológicos estão mudando a forma de conhecer lugares, especialmente os equipamentos móveis como smartphones que congregam em si variadas funções aquém de realizar chamadas, como câmera para realizar fotos e vídeos, navegadores de internet, leitores de arquivos de texto, reprodutores de mídias em geral. Estas facilidades, contribuem indiretamente com o marketing de boca a boca, estimulando amigos ou "seguidores" (followers) a conhecerem destinações.

Contudo, ainda que seu potencial seja bastante conhecido, poucos lugares conseguem utilizá-lo de forma ativa e não passiva, ou seja, oferecendo a integração do ambiente com os dispositivos e não somente aguardando a postagem em redes sociais pelos visitantes. Exemplo disso é o Parque Estadual de Vila Velha, objeto deste estudo. Em seu plano de manejo, criado em 2004, os programas de uso público não tinham possibilidade de ofertar ou prever 0 uso de aplicativos para ampliar a experiência dos turistas, limitando-se assim, às ferramentas da época.

Portanto, considerando que a prática da interpretação se faz fundamental em Unidades de Conservação, por auxiliarem a compreensão dos motivos que levaram a sua conservação e suas especificidades, novas alternativas são lançadas, complementando assim, os meios tradicionais como folders, painéis interpretativos, guias impressos e vídeos educativos.

Desta forma, entende-se que as propostas podem incentivar o turismo pedagógico, auxiliar aos visitantes sobre a postura que deve ser adotada em 
uma área natural e complementar a experiência sobre a fragilidade do meio ambiente, o que pode contribuir na formação de sujeitos ecologicamente responsáveis, ao corroborar com Milan (2007) que destaca o importante papel participativo neste processo.

Por fim, estimula-se que este ensaio seja aplicado na prática pelos atuais gestores do PEVV, uma vez que o investimento de implantação fortalecerá a imagem do Parque, a curiosidade dos visitantes e a conservação in loco. Como sugestão para a continuação desta pesquisa, aconselha-se que estudos de observação em campo sejam realizadas para mensurar a efetiva utilização deste recurso pelos visitantes, bem como a aplicação de entrevistas visando aprimorar os conteúdos propostos.

\section{Referências}

BENI, M. C. Análise Estrutural do Turismo. 10 $10^{\mathrm{a}}$ Ed. São Paulo: Editora Senac São Paulo, 2004.

MELO, M.S. et al. Vila Velha. In: SCHOBBENHAUS, C. et al. (Edit.) Sítios Geológicos e Paleontológicos do Brasil. Disponível em: http://sigep.cprm.gov.br/sitio029/sitio029.htm. Acesso em 08 ago. 2016.

MILAN, P.L. Viajar para aprender: Turismo pedagógico na Região dos Campos Gerais - PR. Dissertação. Mestrado em Turismo e Hotelaria, Universidade do Vale do Itajaí, Camboriú, Santa Catarina, 2007.

MINEROPAR. Parque Estadual de Vila Velha. Disponível em: http://www.mineropar.pr.gov.br/modules/conteudo/conteudo.php?conteudo= 14. Acesso em: 08 ago. 2016.

MINISTÉRIO DO TURISMO. Turismo pedagógico oferece conhecimento e diversão. Disponível em: http://www.brasil.gov.br/turismo/2014/10/turismopedagogico-cresce-no-brasil. Acesso em 11 ago. 2016.

MOREIRA, J.C. Patrimônio geológico em unidades de conservação: atividades interpretativas, educativas e geoturísticas. Tese (Doutorado em Geografia). Universidade Federal de Santa Catarina, Florianópolis, 2008.

NAKAMURA, G.K.Y; MACHADO, A.B. Turismo pedagógico e as possibilidades de ampliação de olhares: roteiro pedagógico na cidade de Santo Inácio - PR. Anais VI Mostra Interna de Trabalhos de Iniciação Científica. Centro Universitário de Maringá - CESUMAR, 23 a 26 de outubro de $2012 . \quad$ Disponível em: http://www.cesumar.br/prppge/pesquisa/mostras/vi mostra/gleisy kelly yasu ko nakamura.pdf. Acesso em 12 ago. 2016.

OMT - ORGANIZAÇÃO MUNDIAL DO TURISMO. Turismo internacional: uma perspectiva global. 2.ed. Porto Alegre: Bookman, 2003.

TELES, A.S; SANTOS, F.F; MOREIRA, J.C. Ação de sensibilização ambiental realizada na Ponte do Rio São Jorge/ Parque Nacional dos Campos Gerais- PR.CONGRETUR: Congresso de Turismo dos Campos Gerais. Anais. Universidade Estadual de Ponta Grossa, UEPG, 2014. 
Leandro Baptista: Universidade Estadual do Centro Oeste, Guarapuava, PR, Brasil.

E-mail: leandro.baptista@live.com

Link para o currículo Lattes: http://lattes.cnpq.br/4353198473576287

Jasmine Cardozo Moreira: Universidade Estadual de Ponta Grossa, Ponta Grossa, PR, Brasil.

E-mail: jasminecardozo@gmail.com

Link para o currículo Lattes: http://lattes.cnpq.br/4244565636923524

Data de submissão: 17 de outubro de 2016

Data de recebimento de correções: 18 de abril de 2017

Data do aceite: 18 de abril de 2017

Avaliado anonimamente 